\title{
Optimization of factors affecting Agrobacterium- mediated genetic transformation in groundnut (Arachis hypogaea L.)
}

\begin{abstract}
The efficiency of Agrobacterium-mediated genetic transformation of groundnut is dependent on various factors such as type and age of explants, antibiotics used for selection, Acetosyringone (AS), duration of co cultivation and infection period. Hence, we have attempted to standardize these parameters to improve the Agrobacterium mediated genetic transformation efficiency in groundnut cv ICG 13942. To evaluate the optimization of factors affecting Agrobacterium mediated genetic transformation in which we used three different explants (Deembryonated cotyledon-DC, Leaflet-LL, Cotyledonary node-CN) and studied, the effect of inoculum concentration $\left(0.5,1.0\right.$ and $1.5 \mathrm{OD}_{600}$ of $A$. tumefaciens $)$, pre culture period (1-11 days), co cultivation period (1-7 days), Acetosyringone concentration $(25-200 \mathrm{mg} / \mathrm{L})$ and antibiotic (Kan) concentration $(25-150 \mathrm{mg} / \mathrm{L})$ on the efficiency of genetic transformation. The transformation was verified by GUS staining and by means of PCR amplification of the uidA and nptII genes. The optimized factors for A. tumefaciens LBA 4404 harboring pBAL2 binary vector mediated transformation in groundnut $\mathrm{cv}$ ICG 13942 are: Pre culture period-3 days, Concentration of A. tumefaciens-1.0 at $\mathrm{OD}_{600}$, Co-cultivation period-4 days, Kan concentration- $100 \mathrm{mg} / \mathrm{L}$ for DC \&CN, $75 \mathrm{mg} / \mathrm{L}$ for $\mathrm{LL}$ explants, Concentration of AS-100mg/L during infection and co cultivation and Cefotaxime concentration- $250 \mathrm{mg} / \mathrm{L}$. Thus, the optimized protocol showed the enhanced transient transformation frequencies such as $18.13 \%$ for DC, $15.33 \%$ for $\mathrm{LL}$ and $12.32 \%$ for $\mathrm{CN}$ explants.
\end{abstract}

Keywords: agrobacterium tumefaciens, arachis hypogaea, GUS expression, npt-II, polymerase chain reaction
Volume 8 Issue 3 - 2018

\author{
Rajinikanth Marka, Rama Swamy Nanna \\ Department of Biotechnology, Kakatiya University, Plant \\ Biotechnology Research Laboratory, India
}

Correspondence: Rama Swamy Nanna, Plant Biotechnology Research Laboratory, Department of Biotechnology, Kakatiya University, Warangal-506009, Telangana, India, Emailswamynr.dr@gmail.com

Received: October 24, 2017 | Published: June 042018
Abbreviations: KAN, Kanamycin; AS, Acetosyringone; CN, Cotyledonary node; LL, Leaflet; DC, De emryonated cotyledon; nptII, Neomycin phosphotransferase; NAA, $\alpha$-Naphthalene acetic acid; BAP, 6-Benzylaminopurin

\section{Introduction}

Groundnut/Peanut (Arachis hypogaea L.) has great potential in third world countries to reduce hunger and malnutrition. ${ }^{1}$ It is widely grown in the semi-arid tropics and India ranks second by $12.5 \%$ in world production. ${ }^{2}$ The production of groundnut is constrained by different biotic and abiotic factors by causing decrease in yield. ${ }^{3}$ To develop stress tolerance through conventional breeding takes longer time and passes through various incompatibility barriers. To overcome these, the biotechnological tools play a great role for developing stress tolerance through introduction of alien genes into elite germplasm of crop plants through genetic transformation technology. ${ }^{4-6}$ The various factors that affect significant differences in T-DNA delivery and transformation included explant type, duration of pre-culture of ex plant, incubation period in bacterial suspension, the concentration of A. tumefaciens during infection, the use and concentration of inducers such as Acetosyringone during infection, antibiotics used for selection and the extent of the co-culture period were optimized to establish a transformation protocol of common bean (Phaseolus vulgaris $).{ }^{7}$ and in chickpea. ${ }^{8}$ Legumes in general are recalcitrant to tissue culture and Agrobacterium mediated transformation is also highly genotype specific. ${ }^{9}$ Several reports have been published on efficient regeneration from diverse explants of peanut, ${ }^{10,11}$ but less success has been recorded with genetic transformation of A.hypogaea. This is due to lack of efficient protocols to induce adventitious shoot buds after the transformation. ${ }^{12-14}$ Recently we have developed the reproducible regeneration protocol in groundnut cv ICG 13942. ${ }^{15-}$ ${ }_{17}$ The aim of this work was to develop a reproducible and efficient method of A. tumefaciens mediated genetic transformation and to evaluate the factors that affect the genetic transformation efficiency by using marker genes (nptII; uidA) and later the same was used for Agrobacterium mediated transformation with the Tc Chitinase-I gene to develop the resistance to Tikka disease in cv ICG 13942 for the first time. Therefore, in the present report we describe the successful transformation and regeneration of putatively transformed plants in groundnut cv ICG 13942.

\section{Material and methods}

\section{Plant material, culture initiation and maintenance}

The mature seeds of groundnut cv ICG 13942, obtained from the germplasm bank of ICRISAT, Patancheru, Hyderabad, Telangana, India were used. Dried seeds were washed under running tap water for 10-15 min followed by treating with Tween-20 (5\%-v/v) for $5 \mathrm{~min}$. Later these were rinsed twice in sterile distilled water. Afterwards the seeds were surface sterilized with $0.1 \%(\mathrm{w} / \mathrm{v}) \mathrm{HgCl}_{2}$ for $8 \mathrm{~min}$ followed by rinsing in sterilized distilled water for 3-4 times under aseptic conditions and soaked for $24 \mathrm{~h}$ in sterile distilled water. The experiments were conducted on modified MS $^{18}$ medium (MMS medium) containing MS basal salts and $\mathrm{B}_{5}$ vitamins, ${ }^{19} 100 \mathrm{mg} / \mathrm{L}$ myoinositol and $30 \mathrm{~g} / \mathrm{L}$ sucrose. The $\mathrm{pH}$ of the medium was adjusted to 
$5.8 \pm 0.02$ with either $0.1 \mathrm{~N} \mathrm{NaOH}$ or $0.1 \mathrm{~N} \mathrm{HCl}$ before addition of agar The medium was solidified with $0.8 \%$ Difcobacto-agar and autoclaved at $121^{\circ} \mathrm{C}$ under $15 \mathrm{psi}$ for $15-20 \mathrm{~min}$. All the cultures were incubated at $25 \pm 2^{\circ} \mathrm{C}$ under cool white fluorescent light (1600lux) with a $16 / 8 \mathrm{~h}$ (light/dark) photoperiod.

\section{Explants preparation}

Three different kinds of explants i.e. de-emryonated cotyledon (DC), leaf let (LL) and cotyledonary node (CN) were used for transformation. Mature dry seeds were imbibed in sterile distilled water for $24 \mathrm{~h}$ after surface sterilization and kept for germination on autoclaved filter paper bridge/boat in $1 / 2$ strength liquid MMS medium in culture tubes. In the case of $\mathrm{CN}$ explants, they were excised from 7 days old in vitro grown seedlings and removed the cotyledons, radical, shoot tip parts, LL explants from axenic seedlings (2 weeks old) were cut into $0.8-1.0 \mathrm{~cm}^{2}$ size and DC explants were isolated from the soaked $(24 \mathrm{hrs})$ seeds and these were inoculated on the following medium: CN explants on MMS+20 mg/L BAP (SIM), ${ }^{15}$ DC explants on $\mathrm{MMS}+0.5 \mathrm{mg} / \mathrm{L} \mathrm{IAA}+15 \mathrm{mg} / \mathrm{L}$ TDZ (SIM) ${ }^{16}$ and Leaflet explants on $\mathrm{MMS}+2 \mathrm{mg} / \mathrm{L} \mathrm{AgNO}_{3}+10 \mathrm{mg} / \mathrm{L} \mathrm{BAP}+0.5 \mathrm{mg} / \mathrm{L} \mathrm{IAA}(\mathrm{SIM}) .{ }^{17}$

\section{Agrobacterium strain and plasmid vector}

The Agrobacterium tumefaciens strain LBA 4404 harboring the binary vector pBAL2 $(18.8 \mathrm{~Kb})$ was used for optimization of transformation protocol in groundnut cv13942. The binary vector pBAL2 consists of reporter gene ( $\beta$-glucuronidase-gus/uidA) by the CaMV 35S promoter and terminator sequences and the selectable marker gene (npt II) driven by the nopaline synthase (NOS) promoter and terminator sequences respectively (Figure 1).

\section{T-DNA Region of pBAL2}

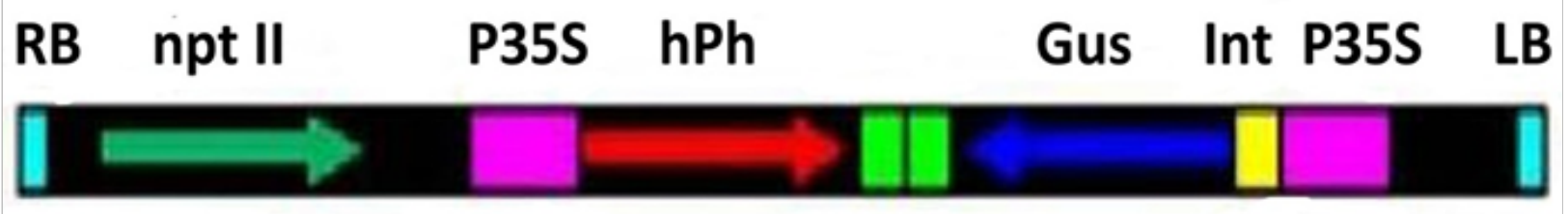

Figure I Linear diagram of T-DNA portion of PBAL2.

\section{Transformation and regeneration of transformants}

The A. tumefaciens strain LBA4404 harboring pBAL2 was grown on YEM agar medium containing $50 \mathrm{mg} / \mathrm{L}$ of Kan and $10 \mathrm{mg} / \mathrm{L}$ Rif. A single bacterial colony was inoculated in $50 \mathrm{ml}$ liquid YEM medium containing the same antibiotics and grown overnight at $28^{\circ} \mathrm{C}$ in an incubator shaker at $120 \mathrm{rpm} .5 \mathrm{ml}$ of this overnight culture was re inoculated in $50 \mathrm{ml}$ fresh YEM liquid medium containing $50 \mathrm{mg} / \mathrm{L}$ Kan and grown overnight. The bacterial cell density was determined at $\mathrm{OD}_{600}$ of 0.5 to 1.5 . Later the bacterial suspension was pelleted at $5,000 \mathrm{rpm}$ for $10 \mathrm{~min}$ and re suspended in $25 \mathrm{ml}$ hormone-free liquid half-strength MS medium. The explants, DC, LL and CN were precultured for 1-11 days on shoot induction medium (SIM) prior to infection with bacteria. The trimmed explants were immersed in Agrobacterium suspension containing $25-200 \mathrm{mg} / \mathrm{L}$ AS for $10-30$ minutes and subjected to manual shaking. Later, the explants were dried on sterile tissue paper and co-cultivated for 1-7 days on SIM along with $100 \mathrm{mg} / \mathrm{L} \mathrm{AS}$ and incubated in the dark at $28 \pm 2^{\circ} \mathrm{C}$. Afterwards the explants were washed with $250 \mathrm{mg} / 1$ cefotaxime for $5 \mathrm{~min}$ followed by rinsing with sterile distilled water thrice for $5 \mathrm{~min}$ and dried on sterile tissue paper. All these explants were cultured on selection medium containing SIM $+75 \mathrm{mg} / \mathrm{L}$ Kan for leaflet and $100 \mathrm{mg} / \mathrm{L}$ Kan for DC and CN explants and $250 \mathrm{mg} / 1$ cefotaxime for 2-3 weeks. The explants with $\mathrm{Kan}^{\mathrm{R}}$ shoots were sub cultured on SIM with $50 \mathrm{mg} / \mathrm{L}$ Kan for further proliferation of shoots. Later each micro-shoot was excised and cultured on MMS $+50 \mathrm{mg} / \mathrm{L} \mathrm{Kan}+0.5 \mathrm{mg} / \mathrm{L} \mathrm{BAP}$ for shoot elongation. After elongation, the micro-shoots were transferred on to root induction medium (RIM) containing $1 \mathrm{mg} / \mathrm{L} \mathrm{NAA}+50 \mathrm{mg} / \mathrm{L}$ Kan . All the cultures were incubated at $25 \pm 2{ }^{\circ} \mathrm{C}$ with a $16 / 8 \mathrm{hr}$ photoperiod.
These $\mathrm{Kan}^{\mathrm{R}}$ plantlets were shifted to plastic cups containing the soil mix, sand: soil: vermiculite $(1: 1: 1)$ and acclimatized in the growth chamber. Established plantlets were transferred to green house and allowed to grow in an earthenware pots for maturity.

\section{Histochemical GUS analysis}

The commercial kit " $\beta$-Glucuronidase Reporter Gene Staining Kit" was performed, following the protocol recommended by the supplier (Sigma Aldrich), after which it was incubated at $37^{\circ} \mathrm{C}$ for $24 \mathrm{~h}$. The shoots were then rinsed twice with ethanol at $70 \%$ and once with acetone at $50 \%$, according to the recommendations of Jefferson et al. ${ }^{20}$ Finally, the number of explants presenting blue coloring and their percentage per treatment was registered by stereoscopic observation.

\section{PCR analysis of putative transformants}

The leaf genomic DNA from $\mathrm{T}_{0}$ plants of cv ICG 13942 was isolated by Cetyl Trimethyl Ammonium Bromide (CTAB) method and used for molecular characterization of putative transgenic by PCR using nptII and uidA gene specific primers. The npt II primer sequences were, (F) 5'-GCT TGG GTG GAG AGG GCT ATT-3' (R) 5'-AGA ACT CGT CAA GAA GGC GA -3' and uidA gene specific primer sequences were, (F) 5'- TTT AAC TAT GCC GGG ATC CAT CGC - 3' (R) 5'- CCA GTC GAG CAT CTC TTC AGC GT - 3'. The PCR for $n p t I I$ was carried out by initial denaturation at $94^{\circ} \mathrm{C}$ for 5 min followed by 35 cycles of $94^{\circ} \mathrm{C}$ for $1 \mathrm{~min}, 54^{\circ} \mathrm{C}$ for $1 \mathrm{~min}$ and $72^{\circ} \mathrm{C}$ for $1.30 \mathrm{~min}$ and final extension at $72^{\circ} \mathrm{C}$ for $10 \mathrm{~min}$. A PCR programme for $u i d A$ gene was carried out by initial denaturation at $94^{\circ} \mathrm{C}$ for $5 \mathrm{~min}$ followed by 35 cycles of $94^{\circ} \mathrm{C}$ for $1 \mathrm{~min}, 64^{\circ} \mathrm{C}$ for 1.30 min and $72^{\circ} \mathrm{C}$ for $2 \mathrm{~min}$ and final extension at $72^{\circ} \mathrm{C}$ for $10 \mathrm{~min}$. Plants 
confirming positive with PCR were taken to maturity and their seeds were collected. The genomic DNA from the untransformed control plants and PCR +ve plants for nptII and uid $A$ genes were used as negative and positive controls, respectively. The amplified fragments were separated by electrophoresis on a $0.8 \%$ agarose gel, using TE buffer. Gels were stained with ethidium bromide, photographed by using gel documentation system (Biorad).

\section{Data analysis}

The transformation efficiency was calculated in different explants.

\section{Results and discussion}

The effect of different parameters on the transformation was carried out. The parameters include pre culture of explants, bacterial cell density, bacterial infection period, co cultivation period, concentration of AS and cefotoxime. Hence, all the experiments were carried out with Agrobacterium tumefaciens strain LBA 4404 harboring the binary plasmid pBAL2 contains nptII and uidA marker genes and co cultivation on MMS medium supplemented with appropriate PGRs (SIM) with different explants (DC, LL and CN) of groundnut cv ICG 13942 .

\section{Factors affecting genetic transformation}

\section{Effect of different OD at $600 \mathrm{~nm}$}

The pre cultured (3 days) DC, LL and CN explants were submerged in bacterial suspension at different $\mathrm{OD}_{600}$ values of 0.5 , 1.0, 1.5 bacterial suspension for $20 \mathrm{~min}$ and were cultured on SIM containing $100 \mathrm{mg} / \mathrm{L}$ AS for 4 days. The bacterial concentration of 1.0 value at $\mathrm{OD}_{600}$ resulted the highest percentage of regeneration with transformation efficiency in DC $(82.60 \%)$, LL $(74.25 \%), \mathrm{CN}$ (61.13\%) explants of cv ICG 13942 (Figure 3a).

\section{Effect of pre-culture period (days)}

To test whether the pre culture period has influence on transformation, the DC, LL and CN explants were cultured on SIM for 1-11 days before the selection on Kan containing medium and also prior to the infection with Agrobacterium strain. Of these, the pre cultured explants for three days on SIM have shown the maximum percentage of response in all the three explants of peanut cv used (Figure 3b). Gradually the percentage of transformation was found to be reduced after $3^{\text {rd }}$ day of pre culture because the explants pre cultured for $5^{\text {th }}, 7^{\text {th }}, 9^{\text {th }}$ and $11^{\text {th }}$ days were unable to receive the Agrobacterium due to the excessive growth of the explant. Among the explants, the DC (69.11\%) and LL (66.23\%) explants have shown the maximum transformation efficiency followed by $\mathrm{CN}$ (64.92\%) explants of cv ICG 13942.

\section{Effect of co-cultivation period}

The pre cultured ( 3 days) DC, LL and CN explants were submerged in bacterial suspension for $20 \mathrm{~min}$ and were co cultivated on SIM containing $100 \mathrm{mg} / \mathrm{L} \mathrm{AS}$ for 1-7 days. Four days of co-cultivation resulted the highest percentage of regeneration with transformation efficiency in DC (66.22\%), LL (60.14\%), CN (57.23\%) explants of cv ICG 13942 (Figure 3c).

\section{Effect of infection period}

The pre cultured explants viz., DC, LL and CN were submerged in bacterial suspension for $10,15,20,30 \mathrm{~min}$, and they were co cultivated on SIM containing $100 \mathrm{mg} / \mathrm{L}$ AS for 4 days. $20 \mathrm{~min}$ infection period had shown the highest percentage of transformation efficiency in DC (58.13\%), LL (52.20\%), CN (48.62\%) explants of cv ICG 13942 (Figure 3d). For more than 20 min infection period, led to the explant abortion caused by bacterial contamination by reducing the transformation frequency.

\section{Effect of antibiotics sensitivity (Kan)}

The pre cultured DC, LL and CN explants were inoculated on SIM with different concentrations $(25-150 \mathrm{mg} / \mathrm{L})$ of Kan (Figure 3e). The percentage of shoot induction response along with multiple shoots development/explants was found to be reduced as the concentration of Kan increased in all the explants tested. More than $90 \%$ of shoot induction response was inhibited at $100 \mathrm{mg} / \mathrm{L}$ Kan in DC, CN explants (Figure $2 \mathrm{a}-\mathrm{f}$ ) and more than $85 \%$ at $75 \mathrm{mg} / \mathrm{L}$ Kan in LL explants (Figure $2 \mathrm{~g}-\mathrm{i}$ ). Beyond that level of Kan, showed the bleaching and necrosis of the explants.
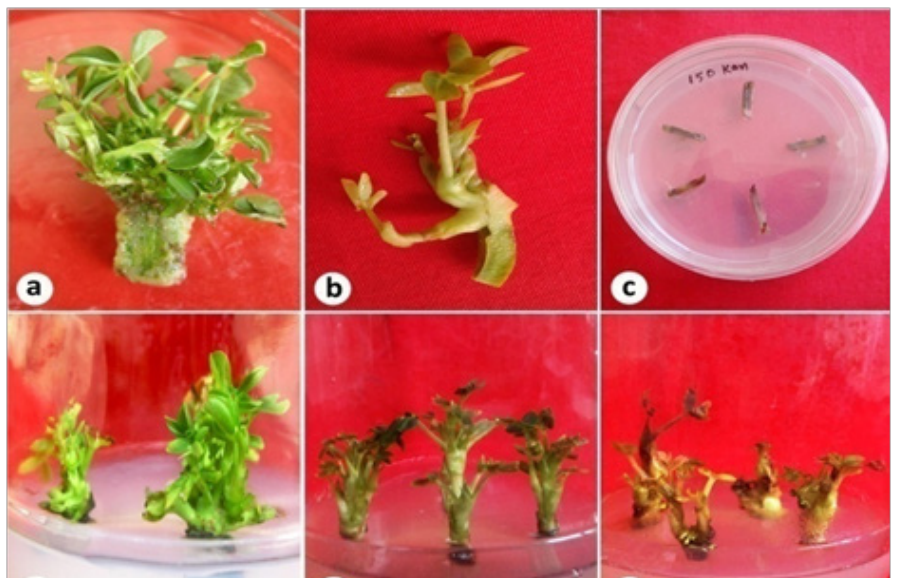

d
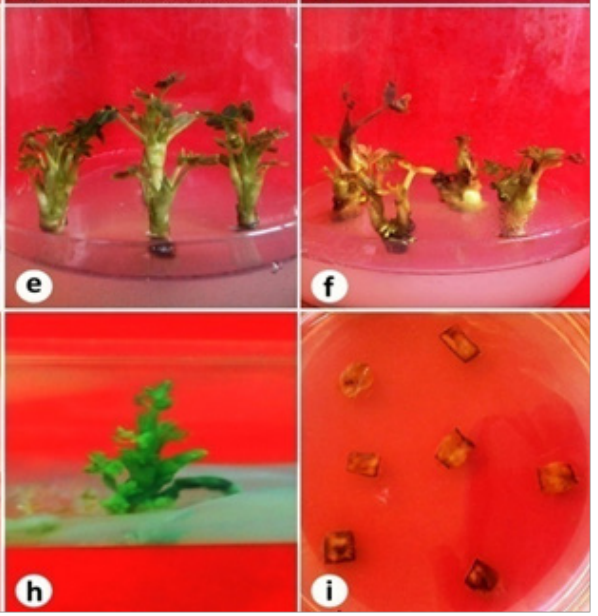

g
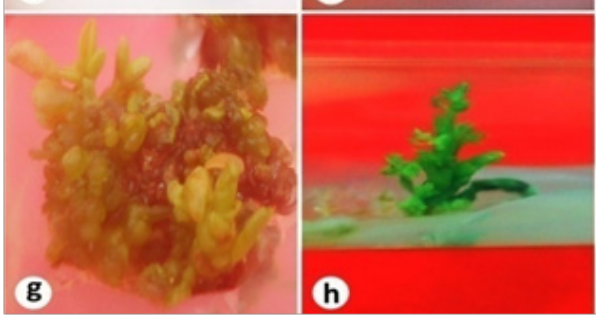

i

Figure 2a-i Determination of antibiotics sensitivity (Kan) in three different types of explants (DC, CN, LL) of groundnut cv ICG I3942.

a-c) Shoot buds proliferation on SIM without antibiotics (control), Shoot buds formation at $100 \mathrm{mg} / \mathrm{L} \mathrm{Kan}$, Inhibition of shoot buds development at $125 \mathrm{mg} / \mathrm{L}$ Kan (Note the necrosis of explants) in DC explants respectively, $\mathrm{d}$-f) Shoot buds proliferation on SIM without antibiotics (control), Shoot buds formation at $100 \mathrm{mg} / \mathrm{L} \mathrm{Kan}$, Inhibition of shoot buds development at $125 \mathrm{mg} / \mathrm{L}$ Kan (Note the necrosis of explants) in CN explants respectively,

$\mathrm{g}$-i) Shoot buds proliferation on SIM without antibiotics (control), Shoot buds formation at $75 \mathrm{mg} / \mathrm{L} \mathrm{Kan}$, Inhibition of shoot buds development at $100 \mathrm{mg} / \mathrm{L}$ Kan (Note the necrosis of explants) in LL explants respectively.

\section{Effect of Acetosyringone (AS)}

Different levels of AS (25- $200 \mathrm{mg} / \mathrm{L})$ was tested and at 100 $\mathrm{mg} / \mathrm{L} \mathrm{AS}$ was found to be the best for enhancing the transformation efficiency in groundnut cv ICG 13942. The maximum percentage 
(76.54\%) of GUS positive explants was observed in DC explants, followed by $71.78 \%$ in LL and $68.21 \%$ in CN explants (Figure $3 \mathrm{f}$ ).

\section{Effect of explant age}

Seven days old seedlings and 24 hours soaked seeds exhibited more GUS expression by showing maximum percentage of transformation efficiency in all the explants used. Transformation efficiency was thus affected by the age of the explant source with optimal transformation efficiencies of $85.13 \%, 73.13 \%$ and $61.09 \%$ for DC, LL and CN explants respectively (Figure $3 g-h$ ).

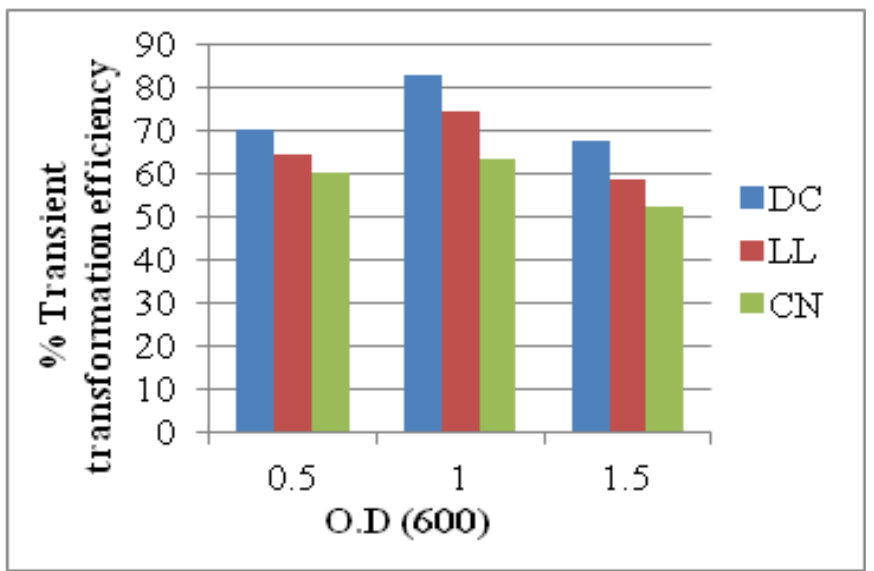

a) Effect of different values of O.D at $600 \mathrm{~nm}$

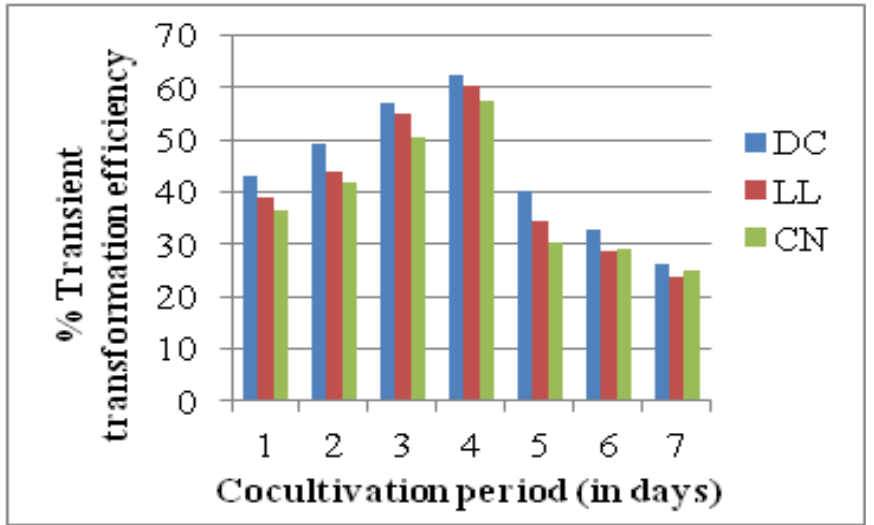

c) Effect of cocultivation period

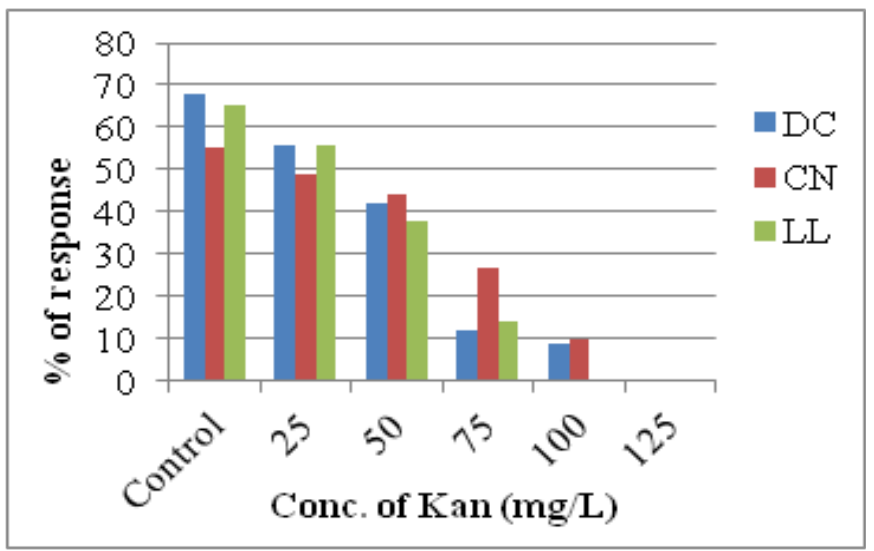

e) Effect of antibiotics sensitivity

\section{Effect of explant type}

Susceptibility to Agrobacterium was dependent on the type of explant. In order to improve the protocol of genetic transformation, LL, CN explants were excised from 7-days old axenic seedlings and DC explants were excised from 24 hours soaked seeds and compared for their transformation efficiencies. The difference in transformation efficiencies was recorded. The highest transformation frequency was observed for DC (18.13\%) followed by LL (15.33\%) and CN (12.32\%) explants (Figure 3i).

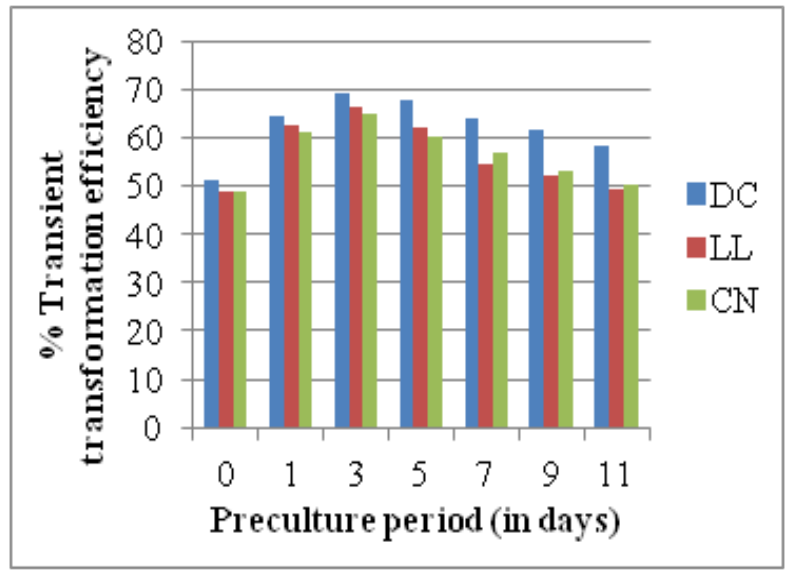

b) Effect of pre-culture period

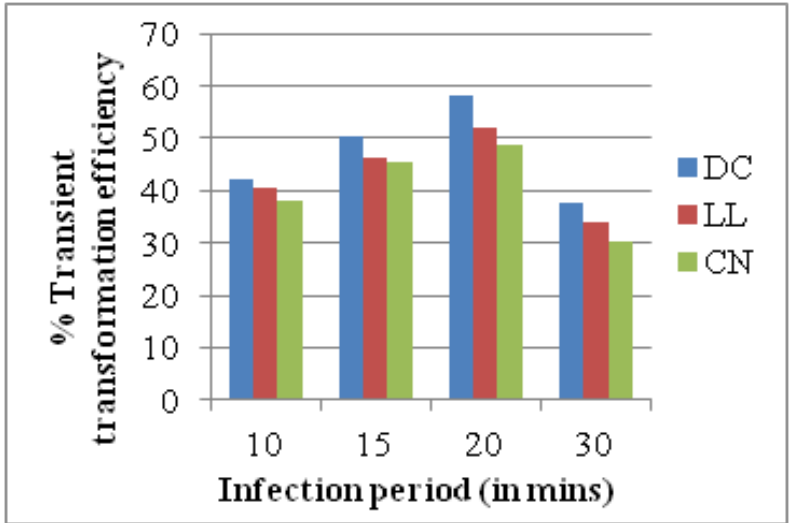

d) Effect of infection period

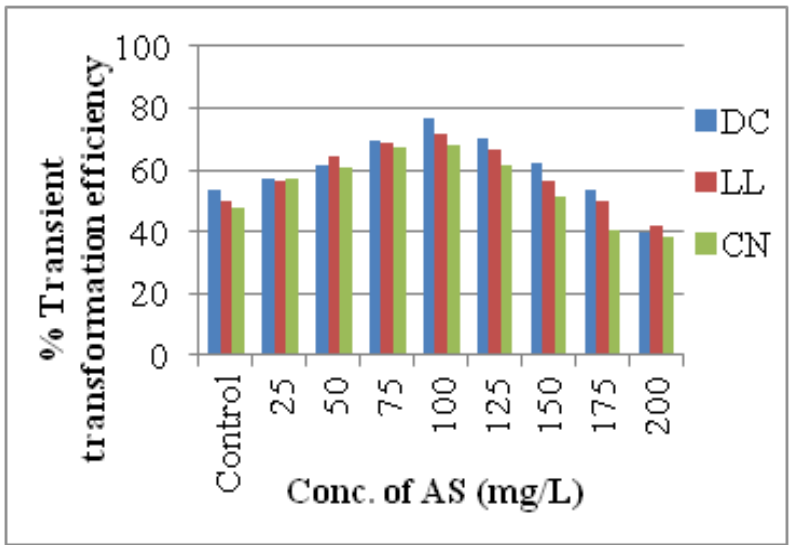

f) Effect of Acetosyringone concentration 

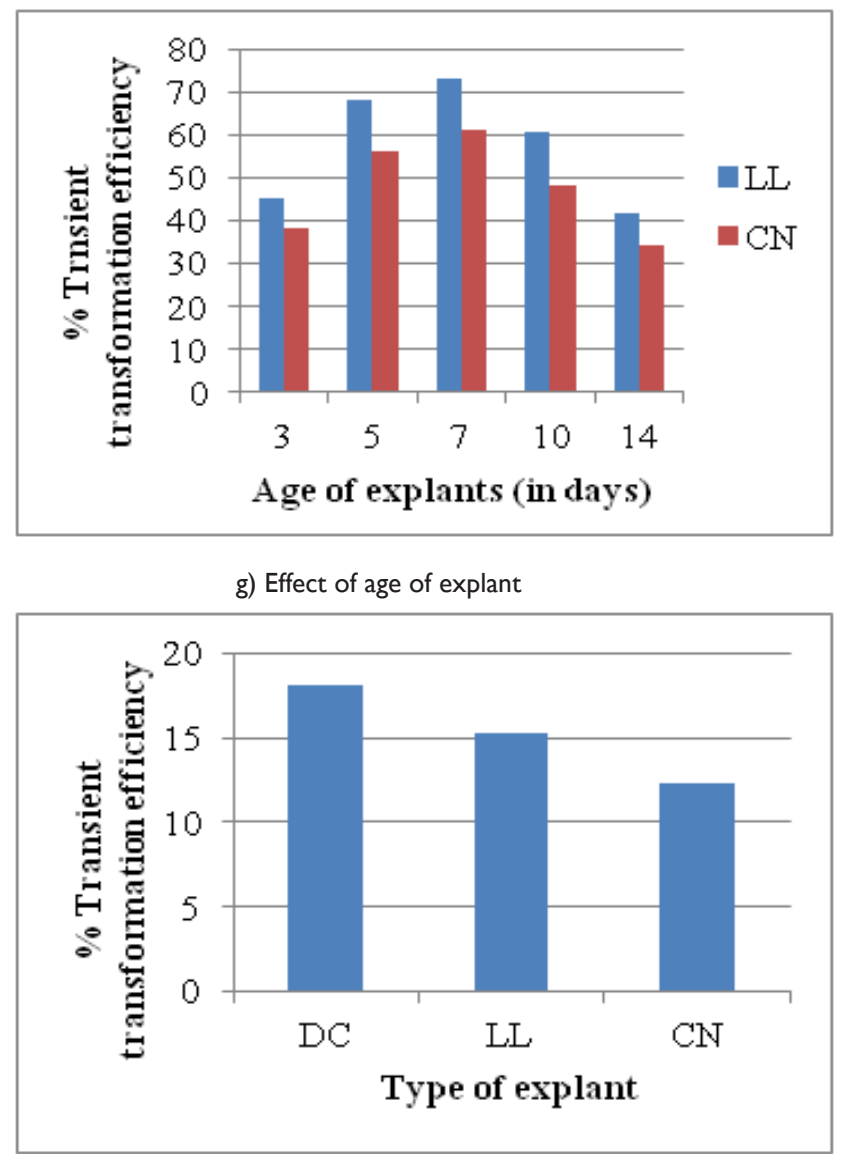

i) Effect of explant type

Figure 3a-i Transient transformation efficiency with different parameters.

\section{Effect of cefotaxime concentration}

After four days of co-cultivation, the explants (DC, LL \& CN) were washed with sterile half-strength MS liquid medium containing $250 \mathrm{mg} / 1$ Cefotaxime to prevent the over growth of Agrobacterium in the infected explants. Subsequently these infected explants were cultured on the selection medium containing SIM $+100 \mathrm{mg} / \mathrm{L} \mathrm{Kan}+250 \mathrm{mg} / \mathrm{L}$ Cefotaxime for DC \& CN, SIM+75mg/L Kan+250mg/L Cefotaxime for LL explants for 2 weeks. Cefotaxime totally arrested the overgrowth of Agrobacterium which causes the death of the explants.

\section{Confirmation of transformants}

All these standardized parameters were used for A.tumefaciens LBA 4404 mediated transformation in groundnut cv ICG 13942. After co cultivation for 4 days, the DC, LL and $\mathrm{CN}$ were cultured on their respective selection medium for 2-3 weeks. The $\mathrm{Kan}^{\mathrm{R}}$ shoots were developed from the transformed cells (Figure $4 \mathrm{a}-\mathrm{c}$ ). The explants with $\mathrm{Kan}^{\mathrm{R}}$ shoots were sub cultured on SIM+50mg/L Kan for further proliferation. The individual micro-shoot was elongated on $\mathrm{MMS}+50 \mathrm{mg} / \mathrm{L} \mathrm{Kan}+0.5 \mathrm{mg} / \mathrm{L}$ BAP. These elongated microshoots were rooted on RIM+1.0mg/L NAA $+50 \mathrm{mg} / \mathrm{L}$ Kan. The $\mathrm{Kan}^{\mathrm{R}}$ plantlets $\left(\mathrm{T}_{0}\right)$ were successfully acclimatized and maintained in the green house (Figure 4d-i).

\section{GUS assay}

To compare transient and stable T-DNA transformation, GUS

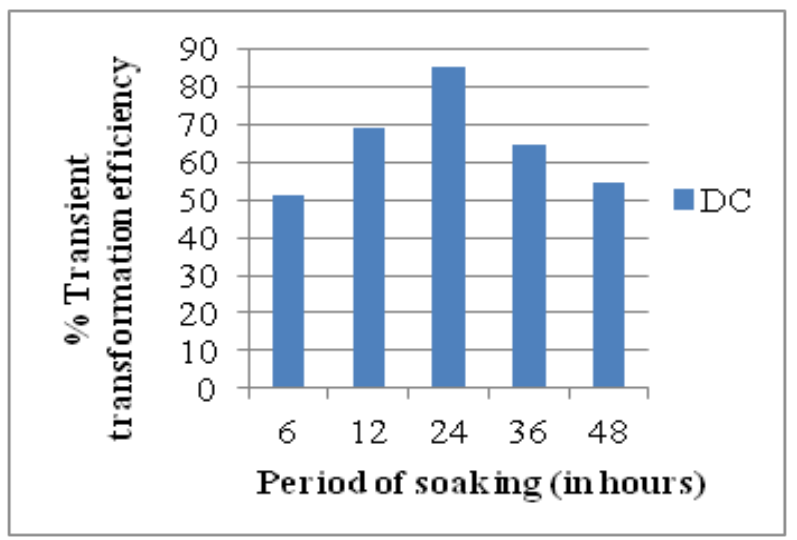

h) Effect of soaking period analysis was done in explants immediately after co-cultivation as well as in young growing tissues of $\mathrm{T}_{0}$ generation of putative transformants. Transient GUS expression was not consistent, however, stable GUS expression was observed in young $\mathrm{T}_{0}$ shoots of $\mathrm{DC}$, $\mathrm{LL}$ and $\mathrm{CN}$ explants (Figure 4F-H). No GUS activity was observed in nontransformed (control) explants (Figure 4E). Explants without pre culture and mechanical injuries, at the site of regeneration, upon co cultivation with Agrobacterium showed no staining (DC, LL and CN). Whereas, pre cultured explants with mechanical injuries showed GUS activity at the wounded regions of the explants. Thus, we have found the typical expression pattern of the CaMV $35 \mathrm{~S}$ promoter regulated uidA gene in transformed tissues. These results show the presence of GUS expression only in transformed tissues, clearly demonstrate the stability of the integrated gene in the putatively transformed plants of cv 13942 of groundnut.

\section{Molecular confirmation}

In the present study, molecular analysis was carried out by using PCR technique in $\mathrm{T}_{0}$ plants. The amplification of the presence of $n p t I I$ and uidA (gus) genes in $\mathrm{Kan}^{\mathrm{R}}$ putatively transformed plants $\left(\mathrm{T}_{0}\right)$ was confirmed. These putatively transformed plants were obtained after three cycles of culture on selection medium after co cultivation with $A$. tumefaciens LBA 4404 strain harboring the binary vector pBAL2. The gene specific primers for $n p t I I$ and uid ' $A$ ' genes were used for PCR amplification and the amplified DNA fragments were found 750bp and $1.9 \mathrm{~Kb}$ respectively (Figure 6) (Figure7). The transformation 
efficiency was estimated on the basis of PCR +ve plants (NPT-II and GUS) developed in the present investigations. Out of $915 \mathrm{Kan}^{\mathrm{R}}$ plants developed only 141 plants showed the PCR +ve (nptII \& gus) with $15.40 \%$ of transformation efficiency in three different types of explants (DC, LL and CN) used in cv ICG 13942 (Figure 5). Thus, the presence of the uidA and nptII genes in the putatively transformed plants $\left(\mathrm{T}_{0}\right)$ of groundnut cvs was confirmed by PCR analysis. PCR analysis revealed the presence of $1.9 \mathrm{~kb}$ uidA and 750bp nptII DNA fragments amplified from the genomic DNA of all $\mathrm{T}_{0}$ transgenic plants. However, PCR products of uidA and nptII genes were not seen in untransformed (control - WT) plants (Figures 6,7), Lane C). All the samples of transgenic plants of $\mathrm{cv} 13942$ gave the predicted size of DNA fragment of uidA gene (1.9Kb) (Figure 6, Lane 1-7). The band was not detected in the DNA sample from an untransformed (control) plant (Figure 6, Lane C). The DNA product with the size of 750bp nptII gene was amplified from total genomic DNA of the $\mathrm{T}_{0}$ transgenic plants of $\mathrm{cv} 13942$ of groundnut (Figure 7, Lane 1-7). This DNA fragment was not detected in the untransformed (controlWT) plants (Figure 7, Lane C). As a positive control, the nptII gene product was also amplified from the pBAL2 plasmid (Figure 7), Lane P). Based on the development of Kan ${ }^{\mathrm{R}}$ plants, GUS assay and PCR detection, the presence of both uidA and nptII genes were confirmed in the $\mathrm{T}_{0}$ transgenic groundnut plants.

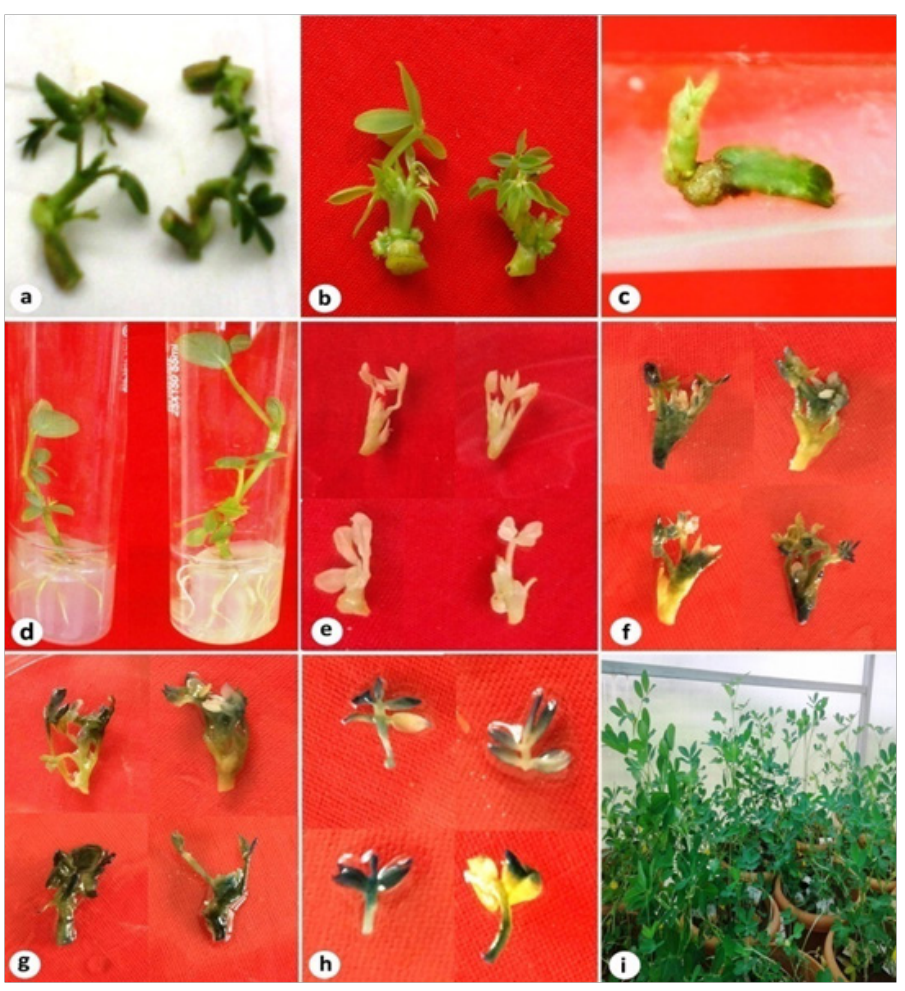

Figure 4a-i Agrobacterium mediated transformation and GUS Assay of transgenic shoots $\left(\mathrm{Kan}^{\mathrm{R}}\right)$ developed from DC, CN and LL explants of $\mathrm{cv}$ ICG I3942 by using the binary vector PBAL2. a-c Induction of $\mathrm{Kan}^{\mathrm{R}}$ shoots on selection medium after 4 weeks of incubation from DC, CN and LL respectively, d) In vitro rooting of shoots on RIM supplemented with 1.0 $\mathrm{mg} / \mathrm{L} \mathrm{NAA}+50 \mathrm{mg} / \mathrm{L}$ Kan (Note profuse rhizogenesis), e) Non transformed shoots (control-WT), f-h) Transgenic shoots developed from DC, LL and CN explants respectively, i) Plants are shifted to plastic pots containing soil mix and maintained in the green house.

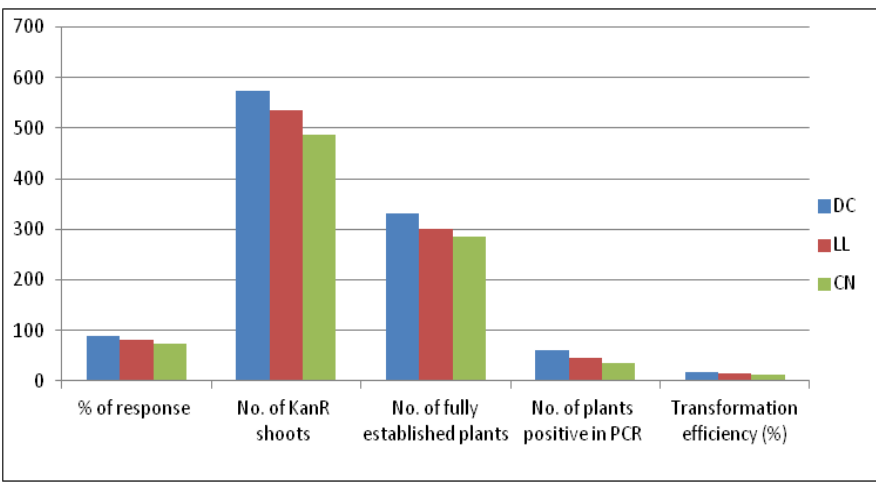

Figure 5 Transformation efficiency in different explants of groundnut cv ICG 13942.

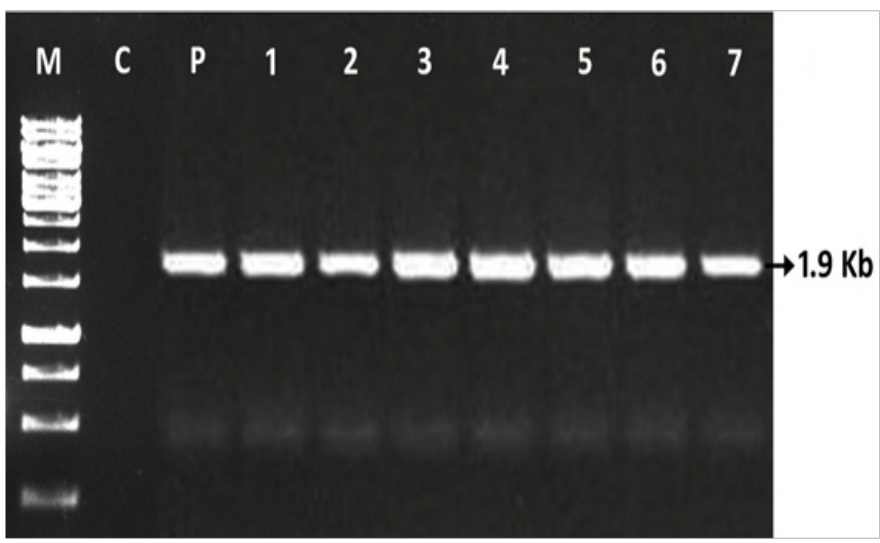

Figure 6 PCR screening of T plants for the presence of the uidA gene using gene-specific primers in cv ICG 13942 of groundnut.

Lane M, DNA marker; Lane C, Control plant DNA (-ve control-WT); Lane P, Plasmid pBAL2 (+ve control); Lanes I-3,T plants developed from DC; Lanes $4-5, T_{0}$ plants developed from LL; Lanes 6-7, $T_{0}$ plants developed from $C N$ explants.

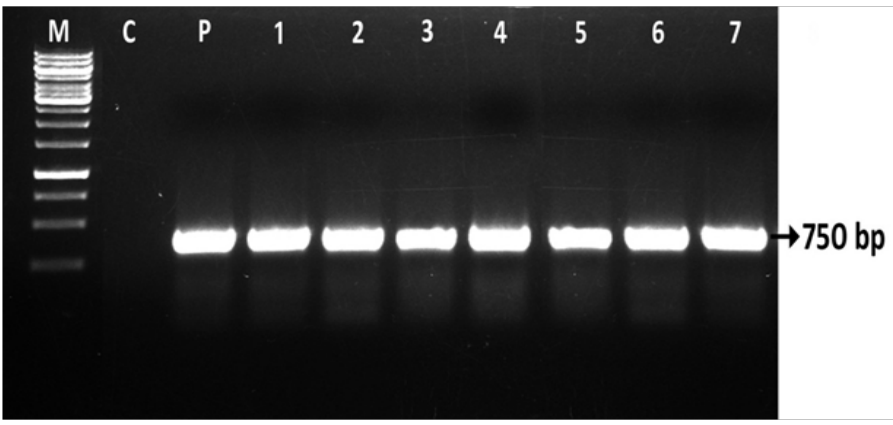

Figure 7 PCR screening of $T_{0}$ plants for the presence of the nptll gene using gene-specific primers in cv ICG 13942 of groundnut.

Lane M,DNA Marker; Lane C, Control plant DNA (-ve control-WT); Lane P, Plasmid pBAL2 (+ve control); Lanes I-3, $T_{0}$ transgenic plants developed from DC; Lanes 4-5, $\mathrm{T}_{0}$ transgenic plants developed from LL; Lanes 6-7, $\mathrm{T}_{0}$ transgenic plants developed from CN explants. 


\section{Discussion}

During the present study, we have attempted for optimization of factors affecting Agrobacterium mediated genetic transformation from individual explant of DC, LL, CN and found best transformation response in DC (18.13\% Transient transformation efficiency) of groundnut cv. ICG 13942. There are various parameters which affect transformation efficiency as explored in groundnut. ${ }^{21}$ The highest transient transformation efficiency was observed for DC (18.13\%) followed by LL (15.33\%) and CN (12.32\%) explants (Figure 3I) in the present investigation. Thus, the transformation efficiency is dependent upon the type of explant in groundnut and similar observations were also made in this crop: $2 \%,{ }^{22}, 16.5 \%{ }^{23}$ when DC was used as explants, $2.2 \%,{ }^{23} 11.3 \%{ }^{23}$ when LL was used as explants and $5.2 \%,{ }^{24} 8.5 \%{ }^{24}$ when used as $\mathrm{CN}$ explants.

Thus, we have achieved the increased level of transformation efficiencies in DC, LL and CN explants in comparison to earlier reports. The density of Agrobacterium suspension plays an important parameter. In the case of groundnut cv ICG 13942, the O.D ${ }_{600} 1.0$ gave maximum transient transformation efficiency $82.60 \%$ in DC, $74.25 \%$ in LL and $63.23 \%$ in $\mathrm{CN}$ explants while an O.D of 1.5 resulted in decreased transient transformation efficiency $67.43 \%$ in DC, $58.63 \%$ in LL and $52.12 \%$ in $\mathrm{CN}$ explants (Figure 3A). Higher bacterial density in the medium may lead to severe necrosis of tissue. ${ }^{25}$ Preculture is an important parameter for genetic transformation of plants because in this step, to reduce the wound stress and enhance the attachment of bacterial cells at the wound site by increasing the entry of T-DNA part into the host cells. Present study showed that, the Transient transformation efficiency (T.T.E) was high $69.11 \%$ in DC, $66.22 \%$ in LL, 64.92 in CN explants after 3 days of pre-culture period while it decreased after 5-11 days of pre culture. Similarly, the importance of pre-culture during transformation studies was also reported in peanut. ${ }^{26}$ Co-cultivation is another important parameter for genetic transformation of plants because in this step, T-DNA is incorporated into plant genomic DNA. ${ }^{27}$ Our results showed that, the T.T.E was high $62.22 \%$ in DC, $60.14 \%$ in LL and 57.23 in CN after 4 days while it decreased after 5-7 days of co cultivation (Figure 3c). Co-cultivation for 4 days was shown to be acceptable in groundnut for better transformation while the longer for co-cultivation does not help to increase transformation efficiency in different legumes. ${ }^{28}$ It is reported that, secretion of Acetosyringone during wounding in plant cells induces the transcription of the virulence genes of Agrobacterium. Addition of Acetosyringone can improve transformation efficiency, in various monocots and some dicot plants which fail to secrete Acetosyringone. ${ }^{27}$

However in our study, addition of $100 \mathrm{mg} / \mathrm{L}$ Acetosyringone showed that, the T.T.E was high at $76.54 \%$ in DC, $71.78 \%$ in LL, $68.21 \%$ in $\mathrm{CN}$ while decreased at $125-200 \mathrm{mg} / \mathrm{L}$. According to our observations $20 \mathrm{~min}$ infection period had shown the highest percentage of transformation efficiency DC (58.13\%), LL (52.20\%) CN (48.62\%) while it decreased after $30 \mathrm{~min}$ (Figure 3d). An extension of infection period for more than $20 \mathrm{~min}$, led to the explant abortion caused by bacterial contamination which reduced the transformation frequency. ${ }^{29}$ Agrobacterium tumefaciens harboring pBAL2 plasmid carrying nptII and uidA genes were used for genetic transformation of groundnut. The present instigation showed more than $90 \%$ of shoot induction response inhibition at $100 \mathrm{mg} / \mathrm{L} \mathrm{Kan}$ in DC, CN explants and more than $85 \%$ at $75 \mathrm{mg} / \mathrm{L}$ Kan in LL explants (Figure 3e). Beyond that level of Kan, showed the bleaching and necrosis of the explants.
Similar findings were also reported in chickpea. ${ }^{30}$ For the effect of cefotaxime $250 \mathrm{mg} / \mathrm{L}$ shows the inhibiting effect of Agrobacterium in DC, LL and CN in groundnut cv ICG 13942. Coherent to our results, in the case of Jatropha curcas, $250 \mathrm{mg} / \mathrm{L}$ Cefotaxime supported the callus induction and shoot regeneration in cotyledon explants and therefore, cefotaxime was used to inhibit Agrobacterium growth after co-cultivation with cotyledon explants. ${ }^{31,32}$ In castor also similar results were found that overgrowth of Agrobacterium was controlled by $250 \mathrm{mg} / 1$ Cefotaxime during transformation of embryo axes and shoot apices. ${ }^{33}$ According to our literature survey, this is the first report of Agrobacterium mediated genetic transformation of groundnut cv ICG 13942. Thus, the protocol developed during the present investigation can be used for genetic transformation experiments to introduce any novel gene into peanut.

\section{Acknowledgements}

We are grateful to University Grants Commission, New Delhi for financial assistance as Fellow under UGC-BSR-RFSMS (F.41/2006(BSR)/7-211/2009(BSR) dt.26-02-2013.). We thank Dr. HD. Upadhyaya ICRISAT, Patancheru, Hyderabad (TS), India for the germplasm (seeds) of cv ICG 13942 and Prof. N. Jayabalan Department of Plant Science, Bharatidasan University, Thiruchurappally, Tamil Nadu, India, for the gift of pBAL2.

\section{Conflict of interest}

The author declares there is no conflict of interest.

\section{References}

1. Enserink M. The peanut butter debate. Science. 2008;322(5898):36-38.

2. United States Department of Agriculture (USDA) Foreign Agricultural Service. Table 13 peanut area, yield, and production; USA; 2014.

3. Jaiwal PK, Singh RP. Improvement strategies for Leguminosae Biotechnology, $10^{\text {th }}$ ed. Focus on biotechnology. Kluwer Academic Publisher, Dordrecht; 2003.

4. Popelka JC, Terryn N, Higgins TJV. Gene technology for grain legumes: Can it contribute to the food challenge in developing countries. Plant Science. 2004;167(2):195-206.

5. Dita MA, Rispail N, Prats E, et al. Biotechnology approaches to overcome biotic and abiotic stress constraints in legumes. Euphytica. 2006; 147(1-2):1-24.

6. Eapen S. Advances in development of transgenic pulse crops. Biotechnology Advances. 2008;26(2):162-168.

7. Zhang Z, Dermot CP, Mitra A. Factors affecting Agrobacterium-mediated transformation of common Bean (Phaseolus vulgaris). J Amer Soc Hort Sci. 1997;122(3):300-305.

8. Akbulut M, Yucel M, Oktem HA. Analysis and optimizaion of DNA delivery into Chickpea (Cicer arietinum L.) seedlings by Agrobacterium tumefaciens. African Journal of Biotechnology. 2008;7(8):1011-1017.

9. Somers DA, Samac DA, Olhoft M. Recent advances in legume transformation. Plant Physiol. 2003;131(3):892-899.

10. Kanyand M, Peterson CM, Prakash CS. The differentiation of emergences in to adventitious shoots in peanut (Arachis hypogae L.). Plant Sci. 1997;126:87-95.

11. Venkatachalam P, Geeta N, Khandelwal A, et al. Agrobacterium mediated genetic transformation and regeneration of transgenic plants from cotyledon explants of groundnut (Arachis hypogaea L.) via somatic embryogenesis. Curr Sci. 2000;78(9):1130-1136. 
12. Livingstone DM, Birch RG. Plant regeneration and micro projectile mediated gene transfer in embryonic leaflets of peanut (Arachis hypogaea L.). Australian Journal of Plant Physiology. 1995;22(4):585-591.

13. Singsit C, Adang MJ, Lynch RE, et al. Expression of a Bacillus thuringiensis cry1A gene in transgenic peanut plants and its efficacy against lesser cornstalk borer. Transgenic Res. 1997;6(2):169-176.

14. Yang H, Singsit C, Wang A, et al. Transgenic peanut plants containing a nucleocapsid protein gene of tomato spotted wilt virus show divergent levels of gene expression. Plant Cell Rep. 1998;17:693-699.

15. Rajinikanth $\mathrm{M}$, Srinivas $\mathrm{P}$, Samatha $\mathrm{T}$, et al. In vitro multiplication potential of cotyledonary node explants in Peanut (Arachis hypogaea L.). Int J Agricult Scie and Res. 2013;3(1):189-196.

16. Rajinikanth $\mathrm{M}$, Ebrahimzadeh $\mathrm{MH}$, Archana $\mathrm{K}$, et al. In vitro direct organogenesis and plantlet formation from de-embryonated cotyledon explants of peanut (Arachis hypogaea L.) Int J Pharma and Bio Sciences.2014;5(3)(B):481-490.

17. Rajinikanth M, Mahitha B, Rama Swamy N. Influence of silver nitrate on leaflet based direct regeneration in Arachis hypogaea L. Vegetos. 2015;28(1):63-69.

18. Murashige T, Skoog I. A revised medium for rapid growth and bioassays with tobacco tissue cultures. Plant Physiol. 1962;15:473-497.

19. Gamborg OL, Miller RA, Ojima K. Nutrient requirements of suspension cultures of soya bean root cells. Exp Cell Res. 1968;50(1):151-158.

20. Jefferson RA, Kavanagh TA, Bevan MW. Gus fusion: $\beta$-glucuronidase as a sensitive and versatile gene fusion marker in higher plants. $E M B O J$. 1987;6(13):3901-3907.

21. Venkatachalam P, Geetha N, Jayabalan N, et al. Agrobacterium mediated genetic transformation of groundnut (Arachis hypogaea L.) An assessment of factors affecting regeneration of transgenic plants. $J$ Plant Res. 1998;111(4):565-577.

22. Freitas VGD, Lacorte C, Martins GS, et al. Identification of competen cells for Agrobacterium transformation and in vitro regeneration in peanut leaf and cotyledon explants. R Bras Fisiol Veg.19979:157-167.

23. Mehta R, Radhakrishnan T, Kumar A, et al. Coat protein-mediated transgenic resistance of peanut (Arachis hypogaea L.) to peanut stem necrosis disease through Agrobacterium-mediated genetic transformation. Indian J Virol. 2013;24(2):205-213.
24. Beena MR, Tuli R, Gupta AD, et al. Transgenic peanut (Arachis hypogaea L.) plants expressing cry1EC and rice chitinase cDNA (Chi11) exhibit resistance against insect pest Spodoptera litura and fungal pathogen Phaeoisariopsis personata. Transgenic Plant Journal. 2008;2(2):157164.

25. Li JF, Park E, von Arnim AG, et al. The FAST technique: a simplified Agrobacterium-based transformation method for transient gene expression analysis in seedlings of Arabidopsis and other plant species. Plant Methods. 2009;5:6.

26. Vasudevan A, Ganapathi A, Selvaraj N, et al. Factors influencing GUS expression in Cucumber (Cucumis sativus Linn). Indian Journal of Biotechnology. 2002;1:344-349.

27. Han J, Wang H, Ye H, et al. High efficiency of genetic transformation and regeneration of Artemisia annua L. Via Agrobacterium tumefaciensmediated procedure. Plant Scencei. 2005;168(1):73-80.

28. Geetha N, Venkatachalam P, Rao GR. Factors influencing production of Agrobacterium mediated genetically transformed calli and plant regeneration in black gram (Vigna mungo L. Hepper). Plant Tiss Cult. 1997; 7:149-152.

29. Bidney D, Seelonge C, Martich J, et al. Micro projectile bombardment of plant tissues increases transformation frequency by Agrobacterium tumefaciens. Plant Molecular Biology. 1992;18(2):301-313.

30. Kar S, Johnson TM, Nayak P, et al. Efficient transgenic plant regeneration through Agrobacterium mediated genetic transformation of chickpea (Cicer arietinum L.). Plant Cell Rep.1996;16(1-2):32-37.

31. Li MR, Li HQ, Wu GJ. Study on factors influencing Agrobacteriummediated transformation of Jatropha curcas. Fen Zi Xi Bao Sheng Wu Хие Bao. 2006;39(1):83-87.

32. Li LC, Qin GJ, Tsuge T, et al. Sporocyteless modulates YUCCA expression to regulate the development of lateral organs in Arabidopsis. New Phytol. 2008;179(3):751-764.

33. Sujatha M, Sailaja M. Stable genetic transformation of castor (Ricinus communis L.) via Agrobacterium tumefaciens - mediated gene transfer using embryo axes from mature seeds. Plant Cell Rep. 2005;23(12):803810 